\title{
Stage IA Pleural Malignant Mesothelioma AJCC v8
}

National Cancer Institute

\section{Source}

National Cancer Institute. Stage IA Pleural Malignant Mesothelioma A/CC v8. NCI

Thesaurus. Code C136409.

Stage IA includes: T1, N0, M0. T1: T umor limited to the ipsilateral parietal with or without involvement of visceral pleura, mediastinal pleura, and diaphragmatic pleura. NO: No regional lymph node metastases. M0: No distant metastasis. (AJCC 8th ed.) 